\title{
Towards a Theoretical Model for Human Resource Management Information Systems, Government Policy and Organizational Performance: A Research Agenda
}

\author{
Selline Indara Akoyo ${ }^{1}$, Muathe SMA $(\mathrm{PhD})^{2}$ \\ I'Department of Human Resource Management, School of Business, Kenyatta University, Kenya) \\ ${ }^{2}$ (Department of Business Administration, School of Business, Kenyatta University, Kenya)
}

\begin{abstract}
This study carries out a critical review of literature on human resource management information system, government policy and organization performance. The motivation for carrying out this literature review is presented and the point of contention is the application of human resource management information system, government policy and organizational performance. The objectives of carrying out this literature review include; to conceptualize the adoption of human resource management Information systems (HRMIS) and organization performance, to analyze the evolution of human resource information system (HRMIS) concept, to identify the theories upon which human resource information system (HRMIS) and organization performance are anchored upon, to critically review the empirical studies and identify the inherent gaps and to identify the factors that influences the adoption of HRMIS. The study reviews the origin of adoption of human resource management Information systems from both academic and management perspective. Factors influencing the adoption of human resource management systems, theoretical framework of human resource management systems whereby four theories namely diffusion theory, social capital theory, behavioral theory and resource based view theory have been discussed. An empirical review was done on thematic issues, methodology, data collection and data analysis. Various studies have been reviewed and analyzed to identify knowledge gaps. Conclusions were drawn and recommendations made based on the literature reviewed. A conceptual frame work alongside measures is proposed for studying human resource management information system, government policy and organizational performance and methodology for the study is also proposed.
\end{abstract}

Keywords: Information and Communications Technology (ICT), Information System (IS), World Wide Web (www), Technology Acceptance Model (TAM), Technology Organizational Environment (TOE), performance

\section{Introduction}

In the recent past many organizations including private companies, universities, Small and Medium Enterprises (SMEs), and government departments have utilized the Internet and the World Wide Web (WWW), as the mainstream tool for communication (Muathe 2010). Firms are now investing heavily in the use of ebusiness Information and Communication Technology (ICT) systems together with internal and external communications in the organization in order enhance their efficiency and effectiveness in terms of service delivery (Maguire and Koh,2004; Muathe, 2010). This has contributed largely on human resource management leading to the adoption of IT related systems in the work place.

According to Shani and Tosani (2010) there is a lot evidence in regard to the transformation of HR functions to most current formats, and this is evident in the popularity of human resource management information systems (HRMIS) within organizations. HRMIS has a key influence on role of the HR function and the workplace. In order for HRM cope up with the market competition, they have to embrace the new technology for them to remain viable. This entails competitiveness which comes about as a result of pressure from competitors due to the adoption advanced systems of operation (Tung and Rieck, 2005; Muathe 2010).

The competiveness is the source of organization's power. The break through and innovations have led to the use of IT systems in the work place. The new inventions pose a challenge to the old-fashioned ways offering HRM support across all sectors for over 10 years (Bondarouk \& Ruel 2009; Chakraborty \& Mansor 2013). Further, more the performance of human resource relies on the use of new technologies .HRM organizations in the recent past strongly rely on the use of HRMIS (Lippert \& Michael Swiercz, 2005; Troshani, Jerram, \& Hill, 2011; Chakraborty \& Mansor 2013).

People and information are key aspects in the work place and greatly have effect on performance of businesses and therefore in order to succeed thus there is need for good management of both in order to attain success (Martinsons, 1994; Teo, Lim, \& Fedric, 2007). This therefore calls for the use of the best ways possible in order to maximize their proficiency. According to Teo et al. (2007) HRMIS can be used to put together these two resources through system use which is likely propel the businesses to achievement of their goals. Thus there is need for the adoption of proper HRMIS systems for organizations to achieve success. The application of 
systems in the work place is a new phenomenon in current times and this is what has sparked my desire to undertake this study.

According to Maguire and Redman (2006) the development of information systems (IS) is perceived to be the domain of the technical expert. This is evident particularly when an organization has the wrong systems in place and if not well managed and this effects the organization negatively. Since technology is not static more problems are likely to be experienced since complexity increases with time and it can get to a point where it can become in tolerable thus impacting on the organization heavily.

According to Bhyuiyan (2014), with the new innovations in the recent past, it is important to embress a real-time information-based, self-service, and interactive work environment. This is to ensure efficiency and effectiveness in performance of work. Innovation is not only associated with corporate success but is also perceived to be extremely important for business survival in the ever changing environment (Goyal \& Pitt, 2007). Employees are required to have various of technical and interpersonal skills and workplace expertise that enables them get used to new technological advancements and to increase performance in organizations (Fernandez, 2001; Combs et al., 2006). Firms are now purchasing and installing sophisticated e-business Information and Communication Technology (ICT) systems in the work place to enhance efficiency and effectiveness in service provision (Maguire \& Koh,2004). This therefore creates a challenge for each and every organization to adopt and embrace the new changes in the environment.

Despite being overtaken by industrial innovation theory in the twentieth century, Miles (2000) noted that "new technology has evolved from a neglected and marginal status to achieving an overwhelming recognition in terms of further studies due the growing perception of services". This is as a result of "noninnovative activities that are superseded by the view that the new changes can play a major role, resulting in greater desire in service innovations" (Barras, 1986; Sundbo, 1997; Evangelista, 2000; Miles, 2000; Djellal \& Gallouj, 2001; Tether, 2002; Drejer, 2004). This new paradigm has acknowledged the service sector contribution especially new processes that complements new technology in business sector specifically from a customer rather than being the driver or innovation agenda (Hertog, 2000).

Rothwell (1992) analyzed historical developments on the evolution of the innovation process models and further notes that new models have developed in five generations, ranging from a simple linear model to a more complicated models. "Technology push and market pull"models are the first and second generation models with simple linear sequential processes. The third generation simultaneous coupling model recognizes interactions and feedback loops between different elements, while the fourth generation interactive model combines the technology push and market pull models and emphasizes the external linkages". "The fifth generation network model perceives the innovation process as a multi factor process, which requires a lot of interaction, networking and knowledge". Despite the fact that the fifth generation models are more complex, they borrow a leaf from the same basic processes like the past models (Rothwell, 1992; Trott, 2005).

According to Muathe (2010) traditionally, it is alleged that information have been created utilizing the systems development life cycle (SDLC which is a common procedure for middle-scale and big-scale software projects, though the utilization of conventional techniques for IS design have not given us a complete assurance in terms of information systems implementation success (Laudon \& Laudon, 2005). It's believed that IS development is being carried out by groups who are inexperienced in the relevant fields of trade and organizational enhancements and this is important for realization of full benefits (Brooke \& Maguire, 1998). IS development is driven by technical objectives of individuals who are technologically savvy but the interests of the organizations are not put at heart and this is where the problems start from for organization. In this case, the systems produced are not customized and so once adopted, they need to adjusted or enhanced to suit the needs of the end user.

HRMS history can be traced from payroll systems in the late 1950s and continued into the 1960s a time when the first computerized worker data was used (Bhyuiyan, 2014). The researcher noted that between (19601980) which is termed as the legislative era, there was processing employee information to enhance efficiently. Further he asserts that by 1980', HRMS systems entailed a number of feature sets and functional capabilities whose key function was to attract, retain and ensure proper employee compensation. HR departments were under pressure to apply new technology that was more affordable and effective in terms of costs during low cost era (1980-1990). This was the key driver that led to the increase in use of systems in the work place.

Both infrastructure and human resources enhance technological capacity of an organization to put in place HRMIS (Oliveira \& Martins, 2010). Organizations with new information system technology are well positioned to adopt HRMIS than those that have no strong technology infrastructure and IT professionals' expertise which may fear adopting of HRMIS. Various authors have perceived technological availability as a huge component that impact IT reception (Kwon and Zmud, 1987; Oliveira and Martins, 2010). Carter and Belanger (2004) noted that three key aspects for e-Government adoption include; relative advantage, image and compatibility". These factors influence the decision of whether to adopt the latest innovation in any given organization or not to. 
Similarly, Teo, (2007) conducted a research in Singapore and discovered that only perceived benefits and compatibility are key determinants of HRMIS acceptance. He further asserts that Relative advantage is correlated to profits, reserves and power, expenditure cut downs and so on. Perceived benefit can is referred as expected paybacks (Troshani, Jerram \& Hill 2011). Alongside the two determinants, organization fit, implementation cost, intricacy or ease of use, efficiency were established as important constructs that affect government institutions (Troshani et al., 2011).

According to Bhyuiyan (2014), there was an increase in demand for HR departments to adopt computer technology to process employee information more effectively and efficiently. This trend resulted in an emergence and increase in the number of vendors who could assist HR departments in automating their programs in terms of both hardware and software. According to Bhyuiyan (2014), companies in the $21^{\text {st }}$ century are under pressure to reduce the cost of the production and to be more responsive to the customers. The only key component towards cost reduction is the use of IT-enabled HRM. This enhances the adoption of HRMIS in the work place.

Changes in the business environment force companies to reorganize themselves and ensure that they engage in activities that enhance their competitiveness in the market place (Franks, 2000; Goyal, 2007).

Yang et al. (2007) expressed that implementation to be effected in businesses top administration can decide despite rejection by junior administrators and staff. Business size, working environment and a talented workforce are vital determinants of effective advancement technology acceptance (Troshani et al., 2011).

Top management support is important since it has an impact on influencing adoption of HRIS. According to Teo et al. (2007) strategic managers or directors support towards technology adoption in a business and workers commitment are key requirements which are affected by the management commitment. Many researches show that management commitment is of key importance on HRMIS implementation (Teo et al., 2007; Yang et al., 2007; Troshani et al., 2011). Adoption of IT to HR departments is slow and this has led to deficiency of HRMIS awareness and expertise lead to low rate of HRIS implementation (Teo et al, 2007). Successful implementation of HRIS demands accessibility to trained workforce in the firm who can enhance its growth and adoption in the organization. The professionals have a good understanding of the features of HRIS.

According to Ferguson and Reio (2009), CEOs and business managers need to evaluate their human resource strategies and practices for them to create and retain a viable workforce that; one that will increase the likelihood of business success. "Similarly, in a meta-analysis examining 92 studies that included 19,319 organizations, Combs, Liu, Hall and Ketchen (2006) found a positive correlation between HPWP ( High Performance Work Practices) and both operational (e.g. retention and productivity) and financial (e.g. accounting or marketing returns) performance". Many research that link organizations' human resource management practices and economic viability in for-profit settings, not much has been done to examine the link between human resource management practices and performance across firms (Fulmer, Gerhart \& Scott 2003).

Ferguson and Reio (2009) tried to address this gap in the literature, and focuses on systems approach to examine how job performance and firm performance are influenced by human resource inputs (e.g. employee skills, motivation) and processes (e.g. reward processes, performance management) in a broad range of organizational types (e.g. manufacturing, governmental). This study will further focus on technology as a moderating variable.

The evolution of adoption human resource management systems concept can be analyzed from two perspectives namely academic perspective and management perspectives. In recent years some scholars have suggested the need for a paradigm shift in the manner in which organizations carry out their activities. (Karakas, 2010; Pirson \& Turnbull, 2011; Rynes et al., 2012). This therefore means we need to have proper systems in place to enhance performance. "Numerous models of innovation have attempted to define and understand innovation as a process and the possible ways in which it can be managed" (Tidd et al., 2005).

Trott (2005), claims that "there are two schools of thought that divide innovation drives and further notes the market view where market conditions provide environment that enhances or curtails the innovation potential of a firm, where issue of importance being a firm's ability to scan their environment and check for opportunities in the market place". Trott (2005) also noted that the resource view is where by an organization own resources are a determinant for their capacity to innovate and shape the markets.

Current studies have researched HRIS reception determinants in Singapore and Australia (Teo et al., 2007; Troshani et al., 2011). The above researchers concurred on existence of a deficit of studies on adoption and suggested the call to further find out the depth influence of the factors affecting adoption of the system. This therefore creates the need for research on adoption in other countries in relation to performance. According to Troshani et al. (2011) more research required to assess HRIS adoption in private enterprises since there is no as research those areas. Thus, the researcher aims to do a literature review on the adoption of HRMIS and its influence on performance. 
HR specialists are interested with managing the various disciplines in the work place and to adequately utilize their importance on employees and customers' satisfaction (Goyal, 2007).Organizational effectiveness in terms of its operations is very essential. Decisions made regarding facilities are key to business decisions. The business initiative on developing facilities management relies entirely on an understanding of the key potential of facilities have on creating quality work conditions that enhance key activities (Goyal, 2007).

According to Wahab (2011) some of the benefits of HRMIS are as follows; the establishment of social network among people; enterprises must optimize computer networks to increase development of human resource management application system, constantly enhancing its application level and accessibility. ; enterprises should establish good corporate culture and trust mechanism to enhance employees' participation and initiative to get involved in enterprise social network and High quality employees often target a certain limited group of people for frequent contact and communication in enterprise social network.

Hendrickson (2003) notes that HRMIS aids firms in their HR practices by improving competence and success as well as providing self-service HR. "HRIS provides information as a consequence of data processing and has user interface applications that can be used to disseminate HR information to employees and functional units managers (Ruel, Magalhaels \& Chiemeke, 2011). Zhang and Wang, (2006) noted that the best way to operate a business in the current times is through the use of relevant Information Technology (IT) in HRM.

Innovation theory has various definitions which differ adversely. Some of the definitions lay emphasis on technology and others on services making it hard to differentiate what it really is. (Goyal, 2007a). The study seeks to achieve the following objectives: To conceptualize the adoption of HRMIS and organization performance, to analyze the evolution of HRMIS concept, to identify the theories upon which HRMIS and organization performance are anchored upon, to critically review the empirical studies and identify the inherent gaps. And to identify the factors that influences the adoption of HRIS

\subsection{Theoretical Review}

\section{Literature Review}

According to Muathe (2010), the model of diffusion of innovations is typically employed in the diffusion of technological inventions over a timeframe by individuals from a social framework. Karshenas and Stoneman (1995) noticed that the three fundamental elements of the theory entail phases of diffusion, innovation features that have an influence on the rate of dispersion. Muathe (2010) asserts that there are five stages through which innovation is seen to progress through and this entails understanding of the innovation, influence by key individuals, dedication to adopt, adoption, and affirmation of the choice.

The five features of innovation attempt to establish the degree to which performance of the development and their key significance to the clients are expected benefits, operational coherence with organizational values, system simplicity, system trial, and the ability to monitor (Karshenas and Stoneman, 1995. To be specific, Powell' (1995) and Tung and Rieck (2005) noted the key relevant factors that need to be facilitated, which depict resource availability which are required for a successful adoption process to take place. He further notes the user groups comprise of trendsetters, initial users, late users, and slackers with the total users at any given time period making an S-shaped implementation arch (Karshenas \& Stoneman, 1995). Trendsetters, and initial users are the categories with high likely hood to adopt and apply new technology.

Attewell (1992) criticized the connection between diffusion model to innovations and he noted that organizational knowledge acquisition and awareness are of key importance in the role they play. Newell (1998) noted that introduction of complicated IT systems presents a knowledge integration issue especially in terms of awareness. This creates a need for the attainment of key information application of new technology (Davis, 1989; Attewell, 1992). The likely users are expected to lay a lot of emphasis on the compatibility of new information, which calls for greater need understanding in terms of both the design aspects and the prevailing norms of the society, previous know-how as well as the prerequisites of likely implementers.

Rip (1995) asserts that trial ability of new technologies influences its acceptance and operation since the actual performance is usually more significant than debates in relation to benefits and operational capabilities. Compatibility is key in the case of HRMIS since its adoption is affected by the existence of network aspects (Church \& Gandal, 2004). Trial ability gives an opportunity trying out a new technology before putting it into its actual use. This is relevant to the early adopters since they rely on available information in comparison to laggards who learn later when technology has already taken roots. However, as Rogers (1995) and Tidd et al., (1997) noted that much of the conventional diffusion of new technologies model is founded on studies of how person's make decisions on acceptance of new technology and this limits use of the model on the study of HRMIS implementation in business context.

However, the diffusion of innovation model is in line with the Marcus' theory (1986), in which he noted that prospective users of inventions asses the conceivable worth that the technological innovation offers to them (Ankem, 2004). Value here is attributed based on benefits and cost incurred to acquire the new technology. 
The introduction of a HRMIS software in an institution be regarded as a new practice since it enhances effectiveness in operational performance.

Barney's (1991) RBV theory of the firm asserts that "the firm's structure; human capital that is the skills, judgment, and level intelligence of the employees; and human resource management systems are key sources of competitive advantage to an organization". RBV theory is of the view that HRMS can enhance competitive advantage through competencies of development and motivation of employees, produce unique social relationships, are deeply rooted in a firm's way of doing things, and contribute to organizational knowledge (Barney, 1991).

Eniola and Entebang (2015) in their study on government policy and performance of small and medium business management noted that resource- based view theory of the firm is of the view that competitive advantage emanates from the wealth assets owned by an organization that are of key value in comparison to those of its competitors. Further research has made significant contribution to its development (Barney, 1996, Grant 2002).

The theory suggests that sustainable exceptional efficiency and competitive advantage of any organization is due accumulation and utilization of resources, managerial choices, factor market imperfections and strategic industry factors (Dharanaj and Beamish, 2003). Company heterogeneity despite the external ecological dynamics are reflected relatively as more significant factors of performance and competitive positioning of a business enterprise both in the indigenous and global market place (Barney, 2001, Tseng et al, 2007; Lu et al., 2010; Bartai 2014).

According to Muathe (2010) the behavioral adoption theories are composed of the Theory of Reasoned Action (TRA), the Technology Acceptance Model (TAM), and the Theory of Planned Behaviour (TPB). Muathe notes that the models are mostly used models in explaining the IT adoption. TRA was originally proposed by Fishbein and Ajzen (1975) in based on the assumption that individuals output in regard to a particular behavior is caused by intentional behavioral intent, which in return determined by attitude and the common norms. Therefore it's logical to make assumptions that TRA is related to voluntary behavior (Muathe 2010).

TAM was originally proposed by Davis in 1989 and initially the theory was used to predict user acceptance of computers but has been adversely used in fields of ICT. The author further notes that TAM relates more to technology in contrast to TRA which is more general. Variable of employee commitment and management commitment can be derived from the TAM model, to determine attitude towards technology. These variables are the perceived usefulness of the technology and the inability to actually use the technology (Davis, 1989).

According to Pedersen and Nysveen (2003), Anckar et al. (2003), and Venkatesh, Moris and Davis, (2003) criticized the model by observing that dividing user believes in regard to technology adoption into two classes tends to overlook other factors like age, sex, experience, and voluntariness that are which are of key importance in ICT adoption. In addition, Muathe further notes that Manueli, Latu and Koh, (2007) criticizes TAM is perceived to be less comprehensive in comparison to the diffusion approach which looks at isuues like time as a key factor of the theory. TAM was also criticized for not considering the effects of personal control factors on behavior, external factors from the environmental like suppliers, customers and competitors (Manueli et al., 2007)

The TPB model came into place to support TRA where to cater for instances where individuals control their behaviour (Ajzen, 1991; Muathe 2010). The model ties to look at factors "behavioural control" to establish possible behavior where individuals are controlled. Successful performance of behaviour does not rely solely on favorable intention but on proper level of behavioral control (Muathe 2010). According to Muathe (2010) TRB and TPB models have not been fully accepted for failing to suggest behavioural attitude and subjective norms and to some extent behavioural control. Battacherjee (2000) asserts that the TAM model can be integrated into TPB with perceived usefulness and user friendliness as key causes of behavioural attitude towards IT adoption. Subjective norms can be assessed by external and interpersonal influence and that the two constitute components of behavior.

To counter the argument, Vankatesh, Moris and Davis, (2003) tried to put together the various models of IT acceptance by merging elements of the following eight prominent models: TRA; TAM; motivational model; TPB; combined TAM-TPB; Model of PC utilization; innovation diffusion theory and social cognitive theory to form Unified Theory of Acceptance and Use of Technology (UTAUT). According to Muathe (2010) the model was validated and it was found out to be reliable especially when used to assess user acceptance in studies involving business organizations and corporations.

Social systems theory was developed by Ludwig (1956) in order to support the theoretical foundation of Human Resource Management (HRM). Social capital theory explores its impact of HRMIS on enterprise social capital, thus impelling academic and partition world to pay close attention to HRMIS function of developing enterprise social capital. It tries to look at the Effect the knowledge creation, technology innovation and operation performance of enterprises. 
According to Midiwo (2015) the social systems model can sensibly be viewed as a specialization of systems thinking; on the other hand as an objective yield of systems science and systems software development, with an accentuation on generalization that it is valuable over a wide scope of systems. Midiwo noted that the SERVQUAL model measures seven service quality dimensions, that is, service quality, system quality, information quality, user involvement, usefulness, user self-sufficiency, user satisfaction to be more ideal in assessing the influence of HRIS on performance. Midiwo noted that this can also be assessed by its indicators, which takes the performance methodology with the first five elements being service provider performance. Midiwo used the constructs of serviperf like service quality, information quality to measure and draw conclusions on the performance of employees in public universities in Kenya.

, singular effect and hierarchical effect

Information Systems Success Model was developed by De Lone and McLean (1992) though they did not empirically test it. The model looked at six viewpoints: system quality, data quality, use behavior, client satisfaction Use; Individual effect and business effect. According to Midiwo (2015) system quality refers to "the features of the technological tool in addition to the processing power of the tool, the dynamism provided by the system, and the quantity of data or resources it can gather.

De Lone and McLean (2003) suggest in their model that "an IS was first developed, bearing containing many characteristics, which are viewed to show high level of performance. The author further noted "the users and managers experience these features by using the system and are either satisfied or dissatisfied with the system or its information products for instance products of HRIS'e-staffing, e-training, e-payroll and eperformance management on the expected performance". The use of the system and its components is important HRMIS has collective impact result on the organizational performance (Midiwo, 2015). De Lone and McLean re-established their model by putting together all key aspects i.e. organizational and individual as one generalized aspect which is advantageous to the organization.

\subsection{Empirical Review}

According to Soriano, (2010) and Eniola and Entebang, (2015) firm performance can be viewed as the ability of a firm to generate change in management and this is through obtaining market opportunities, proper alignment to the surroundings, and bearing key managerial features, new product developments, outstanding qualities, change in the technology applied, are all key factors that can enhance firm performance. Kavanagh $e t$ al. (2012) noted that even though HRMIS comprises hardware and software, it also consists of people, procedures and information. Currently it has been noted that HRMIS has laid more focus on key aspects like staffing, performance and reward administration, automation (Lengnick-Hall \& Moritz, 2003; Bell, Lee, \& Yeung, 2006; Panayotopoulou, Vakola, \& Galanaki, 2007). When the above are correctly implemented this enhance overall HR service levels and reduce costs propelling an organization on an upward curve.

The key functional components of HRIS are input, data maintenance and output. Data entry was the key method of data input but in the recent past modern technologies like scanning have taken the centre stage and enhanced the storage of original documents (Kovach, Hughes, Fagan, and Maggitti, 2002). Once data entry is done there is need for data maintenance and update is important for future reference. The most visible function of HRMIS is output. Production of meaningful performance entails HRMIS to execute and e put in place key measures that will enhance performance by having systems that can easily be comprehended by end users (Kovach \& Cathcart, 1999). HRMIS is comprised of management and ICT. Managing involves personnel, procedures that are intended to operate a business entity successfully while ICT encompasses computer hardware and software (Hendrickson, 2004).

Dileep (2010) indicates that "HRMIS is a combination of HRM and information systems, as HRMIS assists HR managers in performing HR functions more effectively and systematically through the use of technology". Ball,2001;Awazu and Desouza,2003 note that "use of a HRMIS would decrease HR costs by automating information and decreasing the number of HR employees, by helping employees to control their own personal information, and by allowing managers to access relevant information and data, conducts analyses, make decisions, and communicate with others without the help of an HR professional" .

The correct application of HRMIS, is through automation and devolvement of repetitive HR tasks to line management, HR professionals would be able to focus on more business critical and strategic level tasks, such as leadership development and talent management (Lawleretal, 2003). HRMIS also aides HR professionals to be more reliant in the manner in which form their duties like keeping clear records capacity to produce instantaneous information on HR concerns, including labor force training and development that can be used to provide strategic decision making (Hendrickson,2003;Lengnick-Halletal.,2003;Lawleretal.,2004;.Bourini(2011) pressurized the application HRMIS can lead to HR professionals which will be of benefit to organizations. Good application of HRMIS will lead to having good expertise in the organizations.

According to Shani and Tosani (2010) currently, HRMIS have also begun to integrate into the work place manager self-service (MSS), which according to him was defined by Roberts (2004, p. 157) as the use of 
software and the corporate network to automate paper-based personnel-related processes that require a manager's approval, record-keeping or input, and processes that support the manager's job. Shani and Tosani (2010) outline examples of routine transactions that can be done through the MSS as authorizing pay increases, managing work schedules, approving vacation time, and travel expenses, as well as enabling employee access to information. "MSS and ESS create a trend of delegation of responsibilities and activities that were once considered to be the domain of HR professionals and administrative, directly to employees and managers (Lengnick-Hall and Moritz, 2003 Shani \& Tosani 2010).

Currently HR professionals' can use can apply HRIS benefits to enterprises though computing training investment returns, gross revenue, and human-value added (Targowski \& Deshpande, 2001; Sani \& Trosani (2010). When the calculations are done and they show a positive HR's contribution this can be viewed as an indicator of executive management and this is relevant for achievement of organizational goals (Sani \& Trosani (2010). Empirical studies on human resource information systems have used both qualitative and quantitative methods though others use both. The approach chosen determines the philosophical foundation system on relevant to a particular study. Most of the studies on human resource information system reviewed have not indicated the philosophical foundation upon which the research was based.

Dobson (2002), notes that methodologies that have been adopted are those dominated by the kind of social theorists. He further suggests that IS studies need to focus on philosophical approaches to epistemology and ontology and he notes that further Bhaskar's critical realism is a key approach since it views philosophy as operating at the same level as methodological issues. He further states that assessment of information systems is partially determined by political biases and values concerning organization hierarchies, workers' rights and so forth (Dobson, 2002).

According to Reio and Furguson (2009) in their research regarding the relationship between human resource practices and firm performance has been enhanced, there is an increased use of HR systems that lead to attainment of organizations objectives. The study by Charkraborty and Mansor (2013) utilized secondary source of data on the determinants of HRIS implementation which have been categorized into three groups which are business factors, technology context aspects and environmental aspects.

According to Kiarie et al., (2006) and Muathe (2010) they noted that "factors such as the duration of computer experience and top management participation, enjoyment, and voluntariness had significant influence on computer use". According to Ochara, et al., (2008) noted that IT infrastructure and Government had role to play in influencing IT adoption despite this study ignored other determinants influencing lT adoption like individual factors, and organization factors. This study plans to research further on these factors.

Lawson and Hepp (2001) carried out a "time-series quasi-experimental study to measure the effect of human resource practices in relationship to competitive advantage in the banking industry and studied variables such as employee satisfaction, customer results, and business performance". Lawson and Hepp came to a conclusion that human resource practices have a positive and key role on employee commitment, return on expenses (ROE), return on assets (ROA), and on the bank's efficiency ratio (ER).

According to Chakraborty and Mansor (2013) noted that qualitative and quantitate types of research can be employed in innovation studies, though qualitative methods were extensively evident; see for example, (Carter \& Belanger, 2004; Florkowski \& Olivas- arry \& Olivas- et al., 2004; Teo et al., 2007; Troshani et al., 2011; Yang, Lee, \& Lee, 2007) and these investigations were carried out mostly in Western countries and Asian Countries apart from those two of Teo et al. (2007) and Yang et al. (2007). Many studies have been done on the advent of new technology and most have embraced diffusion of innovation theory that was developed by Rogers in 1995 (Carter \& Belanger, 2004; Florkowski \& Olivas- arry \& Olivas- et al., 2004; Teo et al., 2007).

There was deficiency of an adequate sampling frame therefore respondents were sampled using multiple sampling techniques. In the context of Pakistan, other researchers noted the inadequacy of a research culture in the banking sector (Amani Moazzam Baig Mirza \& Nasira Jabeen, 2011) and further noted that any research is perceived to be a "waste of time even by the management" (Nailah Ayub \& Karen Jehn, 2010). In line with the overall culture of sifaarish1 in Pakistan (Islam, 2004), the researcher depended on relied on networking with those in power to identify the organizations that have adopted HRIS and then negotiated physical access to the organization.

Lawson and Hepp (2001) carried out a time-series quasi-experimental study to measure the effect of human resource practices in relationship to competitive advantage in the banking industry and studied variables such as employee satisfaction, customer results, and business performance. Furguson and Reio (2009) carried out a cross-sectional research comprising of 350 corporate experts (91\% executives; $9 \%$ specialists) from a Midwestern US professional firm who acquired a battery of survey procedures through the world-wide web.

Study by Chakrabortya and Mansor (2013), data was obtained from the secondary sources and was analyzed. Trcek (2006) carried out a study was aimed to establish the determinants of HRIS implementation therefore expecting to help out businesses to implement HRMIS precisely and successfully". Trcek used approach is based on systems dynamics and was done in two phases the first phase utilized two basic qualitative 
models were developed, while in the second phase the quantitative models were applied. The study by Muathe (2010) used cross-sectional descriptive survey design and the data was collected using semi structured questionnaire and interview schedule.

According to Midiwo (2015) in her study was informed by positivist philosophy and argues that allows that the researcher to make various assumptions. According to Midiwo (2015) "Positivism belongs to epistemology which can be specified as the philosophy of knowing, whereas methodology is an approach of knowing". Positivism philosophy is of the opinion that only factual knowledge acquired through observation including measurement is trustworthy. Midiwo further argues that in positivism studies the researcher's role is data and interpretation through objective approach and the findings are observable and quantifiable.

According to Ibrahim and Muritala (2015) the effect of government policy on firms can be clarified from either the political or technical point of view. Ibrahim and Muritala argue that politically government policies rely on its political record, philosophy, traditions and the kind of government operations by that nation thus "a Policy in a communist state will vary from that in a democratic state or dominion. Ibrahim and Muritala further note that policies in a politically stable country will not be the same as that from an unstable country.

The author further note that, for a politically stable government they can take sustained businessfriendly decisions that can strengthen local business and this can be strengthened by a strong opposition. Though where we have unstable political systems where opposition boycotts parliament and engage in street demonstrations, businesses are bound to suffer. According to Ibrahim and Muritala (2015) from the technical perspective, some of the policies that can impact on business directly or indirectly are as follows taxation, subsidies, interest rates, and exchange rates.

Ibrahim and Muritala (2015) bank Lending rates and the financial policy of a government have a great impact on its economy. If interest rate high, investment goes down since businessmen would not borrow at high rates. The government is required to create rules which will form a basis for businesses to be "able to compete against each other though these rules will change from time to time". Taxation policy is a key government area that affects organization performance. For example high tax rate on imported products will discourage importation but on the other hand enhancing local produce.

According to Eniola and Entebang (2015) the provision of good government policy is a key component for growth for economies. Eniola and Entebang notes that "performance is constrained by internal factors and external factors, such as the carrying capacity of the environment, government policy or competition". According to Eniola and Entebang noted that the Government can come up with policies that can either enhance or derail the growth of revolutionary technologies, products, and solutions. Eliona and Entebang further noted that the Government can prevent "firm performance when it introduces policy which can restrict the autonomy, as well as the entrepreneurial liberty".

According to Eliona and Entebang (2015) the results of by (Adejugbe 2013; Nguyen, Alam, Perry, and Prajogo 2009; Sobri Minai and Lucky 2011) indicate deficiency of "durable, economic process in these countries prevents the growth of economies, thus the Government should play a key role in creating those conditions". There is a clear emphasize that "government policies cause an impression on" organizations exploitation, organizations close association so as to come up with a combined force that can stop resources utilization (Harvie Narjoko \& Oum., 2010; Okpara, 2011; Eliona \& Entebang 2015). According to Eliona and Entebang (2015) character and span of Government policies have an impact on enterprises.

According to Dessler and Al Ariss (2012); Bartai (2014) urgued that human resource management is concerned by the "procedures and practices" that entail the human resource issues in the work place. According to Bartai urgued that recent advancements in technology have made it imperative to make real-time information based, self - service and interactive work environment. According to Bartai HRIS is believed to be as a "systematic arrangement of HR practices that enable organizations to attain their goals and be able to align themselves to the business strategy in place". This means that HRIS has enhanced and improved organizational performance (Chowdhury, Yunus, Bhuiyan \& Kabir, 2013; Bartai 2014).

According to Usman, Khan, Ikhlaq \& Mujtaba (2012); Bartai (2014), the emergence of information technology in the field of human resource has revolutionized the workplace immensely. Organizational performance is the ultimate achievement of an organization and entails measures, like the existence of targets to be attained, has time duration within which to attain the targets and the realization of efficiency and effectiveness (Gibson et al., 2010). According to Eliona and Entebang (2015) character and span of Government policies have an impact "on an organization's performance". According to Ibrahim and Muritala (2015) the government is required to create rules which will form a basis for businesses to be able to compete against each other though these rules are bound to change from time to time. 


\section{Conclusion And Recommendation}

The role of government in the implementation of HRMIS varies adversely depending on the perspective one is taking. Proper conceptualization is of essence to ensure the right systems are adopted to enhance organizations efficiency and effectiveness. Though the individuals activities of organizations may vary based on the business they are engaged. Human resource department activities are almost the same thought deals with issues relating to human beings are very complex. Further research can be carried out in public and private organization to find out whether the same HRMIS systems are used and any challenges facing them.

As noted Human Resources professionals tend to fear towards technology and tend to avoid it at all costs in their operations since they perceive their career is more of human-oriented. Recently this has been challenged since there is a shift in terms of processes applied within the literature above, more need to be done regarding the use of new HRMIS in the workplace despite the resistance faced during implementation .The purpose of this paper is to provide literature review of the effects of technology on HR. Furthermore the use of online payroll is less costly and ensures the adherence of governmental regulatory and deadlines and it enhances the ability for employees to obtain their data anywhere and makes work easy.

Online security is a key issue which calls for organization to embrace modern technologies to avoid putting employees' information at risk. The adoption of the new technologies requires support from top management as well as employee commitment. Few researches that have been carried out show the relationship between human resource management practices and performance within firms. The HR function in Africa has not embraced the use of new technology to provide integrated services or to communicate more effectively. This therefore creates a gap this research will carry out on the government role on HRMIS implementation on organizational performance.

This research proposes to use decretive survey design specifically cross-sectional survey design for data collection will be used to obtain good results. The descriptive research design framework is more investigative and looks at the variable as it is and goes a notch higher to describe them since it's more investigative in nature. Descriptive design is perceived to be fit and runs hand in hand with the purpose of the research which is human resource information systems, government policy and organizational performance. Since the data will be collected once, cross sectional design will be more applicable to the study. A semi structured questionnaire and interviews schedule will be used as a tool for data collection.

\section{References}

[1]. Adejugbe, A. (2013). Foreign Direct Investment in Nigeria; Overcoming Legal and Regulatory Challenges to Foreign Direct Investments in Nigeria: Is the Nigerian Government Doing Enough? SSRN Electronic Journal. doi: 10.2139/ssrn.2354319

[2]. Ajzen, 1. (1991). A theory of planned behavior: Journal of Organizational Behavior and Human Decision Processes, Vol. 50 (2), $179-211$.

[3]. Amani M. B. Mirza, \& Nasira Jabeen. (2011). Gender Stereotypes and Women in Management, The Case of Banking Sector of Pakistan. A Research Journal of South Asian Studies, 26(2), 259-284.

[4]. Ankem, K. (2004). Adoption of Internet resource-based value-added processes by facultyin LIS education. Library and Information Science Research, Vol. 26(4),482- 500.

[5]. AtteweII, P. (1992). Technology diffusion and organizational learning: The case of business computing. Organization Science, Vol. 3(1): $1-19$

[6]. [6] Askov, E.N. (2000). "Workplace literacy: evaluation of three model programs", Adult Basic Education, Vol. 10, pp. 100-8.

[7]. Bandarouk H. \& Ruel M. (2009), challenges in the digital era. The International Journal of Human Resource Management, 20(3), 505-514.

[8]. Barney, J.B. (2001). Is the resource-based 'view' a useful perspective for strategic management research? Yes. The Academy of Management Review, 26 (1), 41-56.

[9]. Barney, J.B. (1991). "Firm resources and sustained competitive advantage", Journal of Management, Vol. 17, pp. 99-120.

[10]. Bartai J.C (2014).perceived extent of adoption of human resource information systems on performance of public universities in kenya

[11]. Battacherjee, A. (2000). 'Acceptance of e-commerce services: the case of electronicbrokerages' IEEE transaction on the system. Man and cybernetics, 30,411-420

[12]. Bhuiyan F., Mustafa M. C., \& Farzana F.,(2010) Historical Evolution of Human Resource Information System (HRIS): An Interface between HR and Computer Technology, Human Resource Management Research, Vol. 4 No. 4, 2014 , pp. 75-80.

[13]. Brooke, C.\& Maguire, S. (1998), "Systems development - a restrictive practice”, International Journal of Information Management, Vol. 18 No. 3, pp. 165-80.

[14]. Brown, C.B. \& Campbell, B. (2001), "Technical change, wages, and employment inSemiconductor manufacturing", Industrial and Labour Relations Review, Vol. 54, pp. 450-66.

[15]. Callahan, J. \& Reio, T.G. Jr (2006), "Making subjective judgments in quantitative studies:the importance of effect size indices and confidence intervals", Human Resource Development Quarterly, Vol. 17, pp. 159-73.

[16]. Carmeli, A. \& Tischler, A. (2004), "The relationships between intangible organizationalelements and organizational performance", Strategic Management Journal, Vol. 25, pp. 1257-78.

[17]. Carter, L., \& Belanger, F. (2004). The influence of perceived characteristics of innovating on e-government adoption. Electronic Journal of Egovernment, 2(1), 11-20.

[18]. Charkraborty A. \& Mansor (2013). Adoption of Human Resource Information System: Theoretical Analysis, Elsevier.

[19]. Chen, H. \& Hsieh, Y. (2004), "Incentive reward with organizational lifecycle from competitive advantage viewpoint", Human Systems Management, Vol. 24, pp. 155-63. 
Towards a Theoretical Model for Human Resource Management Information Systems, Government ..

[20]. Chowdhury M.S.A., Yunus M., Bhuiyan F. and Kabir M.R., (2013). Impact of Human Resources Information System (HRIS) on the Performance of Firms: A Study on Some Selected Bangladeshi Banks. Proceedings of 9th Asian Business Research Conference 20-21 December, 2013, BIAM Foundation, Dhaka, Bangladesh ISBN: 978-1-922069-399

[21]. Church, J. \& Gandal, N. (2004). Platform competitions in telecommunications: CEPRdiscussion Paper No 4659 in the handbook of telecommunications, Volume 2, M. Cave, S. Majumdar and Vogelsgang (eds.).

[22]. Combs, J., Liu, Y., Hall, A. \& Ketchen, D. (2006), "How much do high-performance workpractices matter? A meta-analysis of their effects on organizational performance", Personnel Psychology, Vol. 59, pp. 501-28.

[23]. Davis, F.D. (1989). "Perceived usefulness, perceived ease of use, and user acceptance of information technology", MIS Quarterly, 13(3), 319-340.

[24]. Den H., D.N. \& Verburg, R.M. (2004). "High performance work systems, organizational culture and firm performance", Human Resource Management Journal, Vol. 14, pp. 55-78.

[25]. Dessler, G. \& AlAriss, A. (2012). Human Resource Management: Strategic Human Resource Management and the HR Scorecard, 10th edition. India: Prentice Hall.

[26]. Dhanaraj, C., \& Beamish, P. W. (2003). A resource-based approach to the study of export performance. Journal of Small Business Management, 41(3), 242-261.

[27]. Eniola, A. A. (2014). The Role of SME Firm Performance In Nigeria. Arabian Journal of Business and Management Review, Vol 3(12), 33-47.

[28]. Eniola A.A \& Entebang (2015). Government Policy and Performance of Small and Medium Business Management International Journal of Academic Research in Business and Social Sciences

[29]. Fernandez, R.M. (2001), "Skill-based technological change and wage inequality: evidence from a plant re-tooling", The American Journal of Sociology, Vol. 107, pp. 273-320.

[30]. Festing, M., \& Eidems, J. (2011). A process perspective on transnational HRM systems--A dynamic capability-based analysis. Human resource management review.

[31]. Fishbein, M., \& Ajzen, I. (1975). Belief, attitude, Intention and behaviour: An introduction to theory and research, Addison-Wesley, Boston, MA.,

[32]. Florkowski, G. W., \& Olivas- -resource information-technology innovations in US and non-US firms. Personnel Review, 35(6), 684-710

[33]. Fulmer, I.S., Gerhart, B. \& Scott, K.S. (2003), "Are the 100 best better? An empirical investigation of the relationship between being a great place to work and firm performance", Personnel Psychology, Vol. 56, pp. 965-93.

[34]. Harvie, C, Narjoko, D., \& Oum, S. (2010). Constraints to Growth and Firm Characteristic Determinants of SME Participation in Production Networks. Integrating Small and Medium Enterprises (SMEs) into the More Integrate East Asia.

[35]. Hendrickson, A. (2004). Human resource information systems: backbone technology of contemporary human resources. Journal of Labour Research , 24(3), 381-394. Journal of Studies in Social Sciences

[36]. Ibrahim T.M. \& Muritala T.A. (2015). Does Government Policies Improve Business Performance? Evidence from Nigeria ISSN 2201-4624 Volume 11, Number 2, 2015, 143-159

[37]. Islam, N. (2004). Sifarish, Sycophants, Power and Collectivism: Administrative Culture in Pakistan. International Review of Administrative Sciences, 70, 311-330.

[38]. Jan M, \& Dr. Nadir. K. (2013). Accountability of HR through Proper Supervision: A Case of Public Sector in Balochistan Province (Pakistan). International Journal of Business and Social Science, 4(3), 102-108.

[39]. Laprade, N. (2006), "The competitive edge: creating a human capital advantage for Kentucky”, Foresight, Vol. 44, pp. 1-6.

[40]. Laudon, K.C. \& Laudon, J.P. (2005), Management Information Systems: Managing the Digital Firm, Prentice-Hall Management, London

[41]. Lawson, T.E. \& Hepp, R.L. (2001), "Measuring the performance impact of human resource initiatives", Human Resource Planning, Vol. 24 No. 2, pp. 36-44.

[42]. Lengnick-Hall, M. L., \& Moritz, S. (2003). The impact of e-HR on the human resource management function. Journal of Labor Research, 24(3), 365-379.

[43]. Lippert, S. K., \& Michael Swiercz, P. (2005). Human resource information systems (HRIS) and technology trust. Journal of information science, 31(5), 340-353.

[44]. Lu, Y. Zhou, L. Bruton, G. Weiwen, L. (2010). Capabilities as a mediator linking resources and the international performance of entrepreneurial firms in emerging economy. Journal of International Business Studies, 41, 419-436.

[45]. Goyal, S. (2007a), "Determining the role of innovation management and measurement in strategic facilities management: ensuring optimization and continuity", PhD thesis, Liverpool John Moores University, Liverpool.

[46]. Karen L. F \&. Reio Thomas G (2009) Human resource management systems and firm performance Department of Educational Leadership and Policy Studies,Florida International University, Miami, Florida, USA

[47]. Karshenas, M. \& Stoneman, P. (1995). Technological diffusion, in the handbook of the economics of innovation and technological change, Stoneman P.(ed.). Oxford, Blackwell.

[48]. Kavanagh, M. J., Thite, M., \& Johnson, R. D. (2012). Human resource information systems : basics, applications, and future directions (2nd ed.). United States of America: Thousand Oaks : SAGE.

[49]. Kiarie, J.N., Ng'ang'a S.L, Kitainge, K.M., \& Too, J.K. (2006). Factors affecting adoption of ICT in small business in Eldoret town, Kenya. Makerere university business school, 12thannual International Management Conference November 21st $-24^{\text {th }}$

[50]. Maguire, S., \& Koh, S.C.L. (2004). An investigation into the use bysmallfirms of new business networks in the North of England. A paper presented at the Twelfth Annual. High Technology Small Firtns 'Coriferente, University of Twente, Enschede, The Netherlands.

[51]. Manueli, S. \& Koh, D. (2007) 'ICT Adoption Models.' 20th Annual 129Conference of the National Advisory Committee on Computing Qualifications

[52]. (NACCQ), Nelson, New Zealand. Samuel Mann and Noel Bridgeman (Eds).Available at Accessed on 11 August 2009.

[53]. Milton Mayfield (2009) (Texas A\&M International University, USA), Jacqueline Mayfield (Texas A\&M International University, USA) and Stephen Lunce (Midwestern State University, USA)

[54]. Muathe, SMA (2010). The determinants of adoption of information and communication technology by small and medium enterprises within the health sector in Nairobi, Kenya

[55]. Nailah A, \& Karen J (2010). The diversity scenario in Pakistani organizations. In Managing Cultural Diversity in Asia (pp. 110129). UK: MPG Books Group.

[56]. Ngai, E.W.T \& Wat F.K.T. (2006). Human resource information systems: a review and empirical analysis. Personnel Review, $35(3), 297-314$. 
[57]. Nguyen, H. T., Alam, Q., Perry, M., \& Prajogo, D. (2009). The Entrepreneurial role of the State and SMEGrowth in Vietnam. Journal of Administration \& Governance, 4(1), 60-71.

[58]. Normalini Md. Kassim, T. Ramayah, \& Sherah Kurnia. (2012). Antecedents and outcomes of human resource information system (HRIS) use. International Journal of Productivity and Performance Management, 61(6), 603-623.

[59]. Oliveira, T., \& Martins, M. F. (2010). Understanding e-business adoption across industries in European countries. Industrial Management \& Data Systems, 110(9), 1337-1354.

[60]. Okpara, J. O. (2011). Factors constraining the growth and survival of SMEs in Nigeria. Management Research Review, 34(2), 156171. doi: $10.1108 / 01409171111102786$

[61]. Panayotopoulou, L., Vakola, M., \& Galanaki, E. (2007). E-HR adoption and the role of HRM: evidence from Greece. Personnel Review, 36(2), 277-294.

[62]. Raza S.H., Batool S.Q., \& Sajid M. A. (2012, February). Benefits and Barriers of Human Resource Information System In Accounts Office \& Azad Jammu \& Kashmir Community Development Program. International Journal of Humanities and Social Science, 2(3).

[63]. Reio, T.G. Jr \& Callahan, J. (2004), “Affect, curiosity, and socialization-related learning: a path analysis of antecedents to job performance", Journal of Business and Psychology, Vol. 19, pp. 3-2

[64]. Reio, T.G. Jr \& Sutton, F.C. (2006), "Employer assessment of work-related competencies and workplace adaptation", Human Resource Development Quarterly, Vol. 17, pp. 305-24.

[65]. Rip, A. (1995). Introduction of new technology: making use of recent insights from sociology and economics of technology, Technology Analysis and Strategic Management, Vol. 7(4), 417-431.

[66]. Roberts, B. (2004), "Empowerment or imposition?”, HR Magazine, Vol. 49 No. 6, pp. 157-66.

[67]. Rogers, E. M. (2003). Diffusion of Innovation (4th ed.). New York, NY: The Free Press. HRM. Management Revue, 15(3), 364-380. Management, 3(1), 84-98.

[68]. Ruel H , Magalhaes, R. \& Chiemeke C.C. (2011) Human resource information systems: An Integrated Research Agenda. Electronic HRM in Theory and Practice (Advanced Series in Management, Volume 8), Emerald Group Publishing Limited, 8, 21 39.

[69]. Samiee, S. (1998). "Exporting and the Internet: a conceptual perspective", International Marketing Review, Vol. 15 (5), $413-26$.

[70]. Sanghvi, A. (2007), "Improving service through online payroll", The CPA Journal, Vol. 77 No. 3,p. 11.

[71]. Shani A. \& Dana V. Tesone (2010) Have human resource information systems evolved into internal e-commerce? University of Central Florida, Orlando, Florida, USA

[72]. Sobri Minai, M., \& Lucky, E. O.-I. (2011). The Moderating Effect of Location on Small Firm Performance: Empirical Evidence. International Journal of Business and Management, 6 (10). doi: 10.5539/ijbm.v6n10p178

[73]. Soud M. A. (2013). E-government system acceptance and organizational agility: theoretical framework and research agendas. International Journal of Information, Business and Management, 5(1).

[74]. Strohmeier, S. (2007). Research in e-HRM: Review and implications. Human resource management review, 17(1), $19-37$.

[75]. Stuart S. \& Redman T. (2006) .The role of human resource management in information systems development Management School, University of Sheffield, Sheffield, UK, and Durham Business School, Durham, UK

[76]. Targowski, A.S. \& Deshpande ', S.P. (2001), "The utility and selection of an HRIS", Advances in Competitiveness Research, Vol. 9 No. 1, pp. 42-56.

[77]. Teo, T.S.H. \& Tan, 1.S. (2002)."Senior executives' perceptions of business- to- , consumer (B2C) online marketing strategies: the case of Singapore", Internet Research, Electronic Networking Applications and Policy, Vol. 11, (3), 258-75.

[78]. Teo, T. S. H., Lim, G. S., \& Fedric, S. A. (2007). The adoption and diffusion of human resources information systems in Singapore. Asia Pacific Journal of Human Resources, 45(1), 44-62.

[79]. Tidd, J., Bessant, 1. \& Pavitt, K. (1997). Managing innovation: integrating technological, market and organisational change, John Wiley and Sons, Chichester.

[80]. Thompson, S. T., Lim, G. S., \& Fedric, S. A. (2007). The Adoption and Diffusion of Human Resource Information Systems in Singapore. Asia Pacific Journal of Human Resource 45(1), 45(1).

[81]. Tomaka, L.A. (2001), "Workforce development in the Midwestern region", Spectrum, Vol. 74, pp. 26-7.

[82]. Trc "ek (2006) Using systems dynamics for human resources management in information systems securityDepartment of Communication Systems-E6, Joz ef Stefan Institute, Ljubljana,Slovenia

[83]. Troshani, I., Jerram, C., \& Hill, S. R. (2011). Exploring the public sector adoption of HRIS. Industrial Management \& Data Systems, 111(3), 470- 488 .

[84]. Troshani, I., Jerram, C., \& Gerrard, M. (2010). Exploring the organizational adoption of Human Resources Information Systems(HRIS) in the Australian public sector. Proceedings of the 21st Australasian Conference on Information Systems (ACIS2010). Brisbane, Queensland.

[85]. Tseng C, Tansuhaj P., HallaganW.,McCullough J. (2007). Effects of firm resources on growth in multinationality. Journal of International Business Studies, y38, 961-974.

[86]. Tung, L.L. \&Rieck, O. (2005). Adoption of electronic government services among business organization in Singapore. Journal of Strategic Information Systems, Vol.14 (4),417-440.

[87]. Usman S., Khan A.F., Ikhlaq K., \& Mujtaba B.G., (2012). The Impact of Information Systems on the Performance of Human Resources Department. Journal of Business Studies Quarterly 2012, Vol. 3, No. 4, pp. 77-91.

[88]. Van-de-Ven, A.H., Polley, D.E., Garud, R. \& Venkataraman, S. (1999), The Innovation Journey, Oxford University Press, New York, NY

[89]. Venkatesh Y., M.G. Morris, G.B. Davis \& Davis F.D. (2003). "User acceptance of information technology: toward a unified view". MIS Quarterly Vol.27 (3), 425-78.

[90]. Wahab A.(2011). The Effectiveness of Human Resource Management Information System (HRMIS) Application in Managing Human Resource at the Perlis State Secretary Office. University Utara Malaysia

[91]. Yang, K. H., Lee, S. M., \& Lee, S. G. (2007). Adoption of information and communication technology: impact of technology types, organization resources and management style. Industrial Management \& Data Systems, 107(9), 1257-1275.

[92]. Zhang, L., \& Wang, H. (2006). Intelligent information processing in human resource management: an implementation case in China. Expert Systems , 369.23, 356- 